\title{
Model Perencanaan Performansi Aerodinamika Turbin Angin Darrieus dengan Metode Multiple Streamtube
}

\author{
Heriyanto Rusmaryadi $^{\left.{ }^{*}\right)}$, Kaprawi Sahim ${ }^{2}$, Ozkar F.Homzah ${ }^{3}$ \\ ${ }^{1,3}$ Jurusan Teknik Mesin, Fakultas Teknik, Universitas Tridinanti Palembang \\ J1. Kapten Marzuki No. 2446, Palembang 30129. \\ ${ }^{2}$ Jurusan Teknik Mesin, Fakultas Teknik, Universitas Sriwijaya \\ J1.Raya Palembang-Prabumulih, km 32,Inderalaya-OI 30622. \\ *E-mail: herirusmaryadi@gmail.com
}

\begin{abstract}
The purpose of this research is to gain aerodynamic performance prediction models of Darrieus wind turbine with multiple streamtube, validate the model obtained with the existing model, and use the validated model to predict and generate new data for designing turbine with different size, shape, type of blade, and wind velocity. Two shapes of turbine blade are also adopted and two sets of data from two different types of blades used in this study to see how big a difference the result. Torque and generated coefficient of power increases with a decrease in drag coefficient which is a function of the Reynolds number. The performance of blade type NACA 0012 is much better when viewed from the coefficient of power.

Keywords: Model, Multiple Streamtube, Darrieus, Coefficient of Power, NACA 0012

Abstrak

Tujuan penelitian ini untuk mendapatkan model pemprediksian performansi aerodinamika dari turbin angin Darrieus dengan metode multiple streamtube, memvalidasi model yang didapat dengan model yang sudah ada, dan menggunakan model hasil validasi untuk memprediksi dan menghasilkan data baru untuk turbin dengan skala, ukuran, bentuk, jenis sudu, kecepatan angin yang berbeda. Dua bentuk sudu rotor turbin juga diadopsi dan dua kumpulan data dari dua jenis sudu yang berbeda dipergunakan dalam penelitian ini untuk melihat seberapa besar perbedaan hasilnya. Torsi dan koefisien daya yang dibangkitkan meningkat seiring penurunan koefisien drag yang merupakan fungsi dari bilangan Reynold. Sudu jenis NACA 0012 jauh lebih baik perfomansinya bila dilihat dari koefisien dayanya.
\end{abstract}

Kata kunci: Model, Streamtube Jamak, Darrieus, Koefisien Daya, NACA 0012

\section{PENDAHULUAN}

Turbin Darrieus kembali diper-bicangkan setelah hampir 15 tahunan ditinggalkan tanpa pengembangan berarti. Untuk pengem-bangannya diperlukan model pemprediksian performansi yang bagus untuk pengoptimalan penskalaan dimensi turbin angin sumbu vertikal (VAWT) ini secara eksperimental. Model ini harus bisa secara akurat memprediksi performansi rotor skala kecil yang data eksperimentalnya sudah ada yang selanjutnya bisa dipakai untuk memprediksi performansi dalam skala yang lebih besar, maupun dengan variabel-variabel lainnya yang bisa diubah-ubah. Besaran variabelvariabel ini dibatasi oleh pengkondisian pemodelan, yaitu; penggunaan data sekunder, kecepatan angin bebasnya diasumsikan cukup rendah $(\leq 7 \mathrm{~m} / \mathrm{s})$, dimensi turbin relatif kecil $(1 \mathrm{~m}$ s.d. $2 \mathrm{~m})$, jumlah sudunya dua atau tiga buah, konfigurasi sudu lurus, dan jenis sudunya adalah NACA 0012 dan NACA
0018.

Secara teoritis, turbin Darrieus memiliki keunggulan untuk menerima angin dari segala arah, mekanisme di turbinnya bisa diletakkan di tanah, mudah dijangkau [5] dan bisa bekerja dengan kecepatan angin bebas yang lemah. Kelemahannya adalah efisiensi yang masih agak rendah tetapi bisa ditingkatkan dengan pereduksian drag [8], sudut attack bervariasi sehingga hanya akan ada drag dan distribusi ke torsinya negatif [5], serta ketidakmampuannya untuk berputar sendiri di awal pergerakan karena rasio antara kecepatan sudunya dibandingkan kecepatan angin bebas (biasa disebut TSR, tip speed ratio) masih rendah. Tetapi dengan upaya-upaya perbaikan, diharapkan bisa diatasi dengan beragam strategi; pengoptimalan desain sudu lewat proses otomatis penentuan luas penampang terbaik pada kondisi tertentu [1], penambahan peralatan yang berprinsip drag atau digabung dengan turbin Savonius [6], atau bisa juga dengan desain sudu dengan pitch yang bervariabel [4], [2].

Turbin Darrieus yang dipakai adalah jenis sudu 
lurus, yaitu Darrieus tipe $\mathrm{H}$ atau Gyromills. Tipe ini merupakan modifikasi dari turbin Darrieus melengkung (egg-beater). Secara teoritis, turbin ini memiliki sejumlah keunggulan, salah satunya adalah menghasilkan daya output yang lebih besar karena daerah cakupan sudunya (swept area) lebih luas sehingga bisa mengekstraksi energi dari angin lebih banyak.

Secara teoritis, ada beberapa teori yang bisa dipakai untuk pemodelan prediksi performansi ini. Dimulai dengan teori streamtube tunggal yang dikembangkan Templin [7], streamtube jamak [11], streamtube jamak berganda, vorteks, garis lifting berkecepatan tinggi dan teori sirkulasi lokal. Dari teori-teori ini, secara logika, yang bisa dipakai adalah yang terbaik. Hanya saja ada pertimbangan lainnya yang perlu diperhatikan. Pertama-tama, penelitian ini adalah langkah pembuka dari penelitian potensial selanjutnya. Kedua, ruang lingkup penelitian yang diharapkan untuk permasalahan yang tidak terlalu rumit, meski tak berarti sesuatu yang sepele. Sehingga dipilihlah teori yang menengah kerumitannya, selain karena lebih masuk akal juga karena adanya batasan waktu pelaksanaannya. Sehingga teori streamtube jamaklah yang dipilih, dengan pertimbangan teori yang lebih advance bisa diakomodasi pada penelitian selanjutnya.

Penerapan teori streamtube jamak ini dalam pemodelan dengan menggunakan beberapa rumus, antara lain:

Gaya streamwise

$\frac{N \cdot F_{x}}{2 \pi \cdot \rho \cdot r \cdot \Delta h \cdot \sin \theta \cdot U_{\infty}^{2}}=\frac{U}{U_{\infty}} \cdot\left(1-\frac{U}{U_{\infty}}\right)$

Komponen gaya di elemen sudu tanpa dimensi

$$
\left.\begin{array}{c}
F_{t}^{+}=\frac{F_{t} \cdot \sin \beta}{\frac{1}{2} \cdot \rho \cdot \Delta h \cdot c \cdot U_{T}^{2}}=c_{t} \cdot\left(\frac{U_{R}}{U_{T}}\right)^{2} \\
F_{n}^{+}=-\frac{F_{n} \cdot \sin \beta}{\frac{1}{2} \cdot \rho \cdot \Delta h \cdot c \cdot U_{T}^{2}}=c_{n} \cdot\left(\frac{U_{R}}{U_{T}}\right)^{2}
\end{array}\right\}
$$

Koefisien tangensial dan normal

$$
\left.\begin{array}{l}
c_{t}=c_{L} \cdot \sin \alpha-c_{D} \cdot \cos \alpha \\
c_{n}=c_{L} \cdot \cos \alpha+c_{D} \cdot \sin \alpha
\end{array}\right\}
$$

Vektor kecepatan relatif

$$
\tan \alpha=\frac{U \cdot \sin \theta \cdot \sin \beta}{U \cdot \cos \theta+U_{t}}
$$

Torsi elemental streamtube

$$
T_{S}=\frac{1}{2} \cdot \rho \cdot r \cdot c_{t} \cdot \frac{c \cdot \Delta h}{\sin \beta} \cdot U_{R}^{2}
$$

Torsi total

$$
T_{B}=\sum_{1}^{N_{S}} T_{S}
$$

Koefisien daya

$$
C_{p}=\frac{\sum_{1}^{N_{t}} \sum_{1}^{N_{S}}\left(\frac{N \cdot c}{2 \cdot R \sin \beta} \cdot \frac{U_{T}}{U_{\infty}} \cdot\left(\frac{U_{R}}{U_{\infty}}\right)^{2} \cdot c_{t}\right)}{N_{t} \cdot \sum_{1}^{N_{S}} \frac{r}{R}}
$$

Tujuan dari studi ini adalah untuk mengembangkan suatu model pemprediksian performansi turbin angin sumbu vertikal Darrieus berdasarkan data eksperimental sekunder yang sudah ada, sehingga model yang didapatkan dapat divalidasi dengan model asli yang sudah ada sebelumnya dari hasil data eksperimentalnya yang diambil tadi. Selain itu, model yang sudah divalidasi dipakai untuk memprediksi turbin yang sama dengan jenis sudu, dimensi, kecepatan angin yang berbeda untuk mendapatkan data performansi yang baru. Sehingga bisa diteliti beragam jenis sudu lainnya, bilangan Reynold, soliditas, dimensi, jumlah sudu, radius turbin, panjang chord, kecepatan angin dan variabel lainnya yang berbeda.

\section{METODE}

Penelitian ini menggunakan metode numerik dalam penganalisisan datanya. Karena itulah, dalam pelaksanaannya, penelitian ini lebih mengedepankan pembelajaran teoritis, pencarian data, penganalisisan data dan validasi/verifikasi datanya dengan menggunakan software komputer. Sehingga alat atau perlengkapan yang diperlukan dalam penelitian adalah sebuah komputer personal ataupun komputer portabel dengan beragam software pihak ketiga sebagai pendukung, misalnya; program bahasa pem-programan dan programprogram aplikasi pengolah kata, lembar kerja, dll.

Pada awalnya teori yang akan dipergunakan untuk mengetahui seluk-beluk sistemnya secara teoritis dipahami. Setelah didapatkan gambaran teorinya, dimulailah tahap awal untuk mencari data sekunder yang bisa dijadikan acuan. Mendapatkan datanya tidak terlalu sulit, hanya saja bagian yang paling sulit adalah mencari data yang siap dan sudah ada perhitungan performansinya yang akan dijadikan sebagai pembanding atau validitas. 
Setelah datanya siap, dimulailah tahap ketiga, yaitu pembuatan program untuk memprediksi performansi turbin Darrieus yang datanya sudah ada. Di tahap inilah sebenarnya inti dari penelitian ini karena di sinilah terjadi proses analisis, penulisan program, trial and error, analisis lagi, pengecekan data, analisis lagi, dan pemvalidasian model.

Sedangkan data yang dipakai dalam penelitian ini berasal dari beberapa sumber. Untuk data airfoil NACA 0012 (untuk bilangan Reynold $0.3 \times 10^{6}, 3 \times$ $10^{6}$ dan sudut attack $<30^{\circ}$ ) didapatkan dari [3], begitu juga dengan nilai koefisien drag (pada sudut attack $=0$ ). Sedangkan data untuk airfoil NACA 0012 (untuk sudut attack $>30^{\circ}$ ) didapatkan dari [9]. Selanjutnya untuk data airfoil NACA 0018 (untuk bilangan Reynold $\approx 0.3 \times 10^{6}$ dan sudut attack $0^{0}$ s.d. $180^{\circ}$ ) didapatkan dari [10].

\section{HASIL DAN PEMBAHASAN}

\section{Pemvalidasian Model}

Setelah model didapatkan, model tersebut perlu divalidasi dulu untuk melihat kevalidannya. Untuk itu, hasil dari model yang didapatkan perlu dibandingkan dengan hasil dari model yang sudah sudah ada sebelumnya.

Pada Gambar 1 ditampilkan output dari kedua model di atas, untuk jenis sudu NACA 0012, bilangan Reynold $=0.3 \mathrm{e}+06$, dan jumlah sudu 2 buah. Pemodelan yang sudah dilakukan bisa dikatakan memuaskan karena model yang dihasilkan mendekati model yang sebelumnya. Secara persentase, model yang didapat memiliki selisih (atau bisa saja disebut sebagai "error") sebesar $0.19 \%$. Sehingga berdasarkan persentase tersebut, bisa dikatakan model yang dihasilkan sudah memuaskan dan dapat dijadikan "role model" dalam memprediksi performansi aerodinamis turbin angin Darrieus karena memiliki kemiripan sebesar 99.81\%. Hanya saja, kita masih memerlukan buktibukti tambahan lagi.

Lalu kedua model dibandingkan dengan kondisi yang berbeda. Langkah awalnya, dengan mem-plot grafik gabungan untuk sudu NACA 0012 untuk beragam jumlah sudu (Gambar 2). Selanjutnya, jenis sudunya diganti menjadi NACA 0018 , bilangan Reynold $\approx 0.3 \mathrm{e}+06$ dengan beragam jumlah sudu juga (Gambar 3).

Dari gambar 2 dan 3 terlihat bahwa model yang sudah dihasilkan bisa dikatakan cukup berhasil dan cukup bisa dipercaya untuk dijadikan model untuk memprediksi performansi aerodinamika sebuah turbin angin Darrieus. Hal ini disebabkan karena hasil yang didapatkan memang seperti hasil yang diharapkan bila dibandingkan dengan kurvakurva performansi hasil dari studi eksperimental.

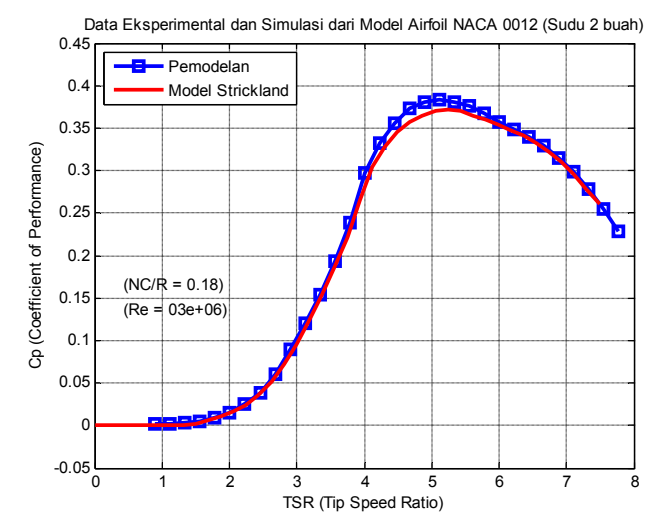

Gambar 1 Model yang didapat vs model dari data

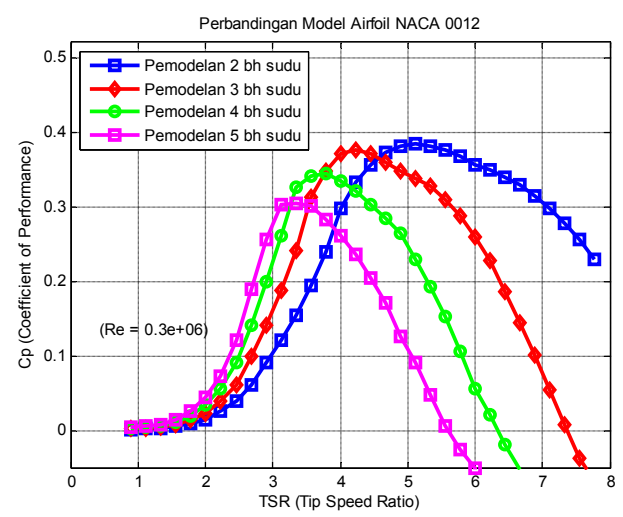

Gambar 2 Perbandingan kedua model dengan beragam jumlah sudu (NACA 0012)

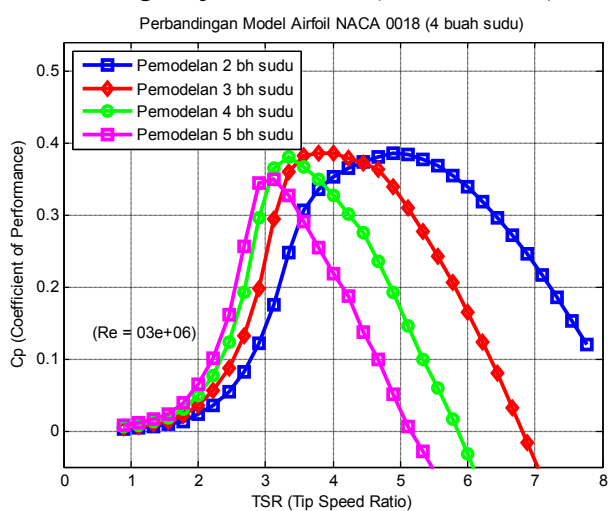

Gambar 3 Perbandingan kedua model dengan beragam jumlah sudu (NACA 0018)

\section{Analisis Hasil Pemodelan}

Pada Gambar 1 terlihat bahwa pemodelannya sudah memuaskan sehingga pantas dijadikan acuan dalam prediksi performansi aerodinamis dari turbin angin Darrieus. Dari Gambar 2 terlihat bahwa semakin banyak jumlah sudunya, maka performansi aerodinamisnya akan mengalami penurunan (yang tercermin dari penurunan koefisien performansi secara keseluruhan). Sehingga bisa disimpulkan 
penggunaan jumlah sudu disarankan hanya 2 atau 3 buah saja karena dengan jumlah sudu yang banyak penambahan daya yang dihasilkan tidak sebanding dengan penurunan performansi yang terjadi. Selain itu (dengan jumlah sudu lebih dari 3 buah), maka performansinya akan terus menurun dimulai dari nilai TSR $>3.5$. Bahkan malah bernilai minus.

Untuk penggantian jenis sudunya menjadi NACA 0018, dari Gambar 3 terlihat bahwa terjadi pola yang sama seperti pada jenis sudu NACA 0012 dimana penggunaan jumlah sudu disarankan hanya 2 atau 3 buah saja.

Selanjutnya adalah penerapan pemodelan untuk jenis turbin Darrieus tipe $H$. Untuk penerapannya dilakukan dengan pemakaian nilai $\beta$ yang konstan yaitu sebesar 900, dimana dengan penggunaan nilai ini, persamaan-persamaannya menjadi lebih seder-hana karena nilai sinus 900 adalah 1 .

Penerapan pemodelan untuk turbin Darrieus tipe $\mathrm{H}$ ini, hasilnya cukup berbeda bentuk maupun skala plot-nya jika dibandingkan dengan hasil pemodelan turbin Darrieus tipe egg-beater. Perbedaan yang cukup mencolok terletak pada daerah TSR kisaran di atas angka 2. Di sana terlihat bahwa secara umum hasil keduanya memiliki pola yang sama, hanya saja berbeda skala atau magnitude-nya.

Secara teoritis, penurunan performansi disebabkan adanya getaran di bagian atas dan bagian bawah daerah sudu-sudunya. Alasan inilah yang pada awalnya membuat desain turbin Darrieus tipe $\mathrm{H}$ diubah menjadi Darrieus tipe egg-beater. Kekurangan ini akan menyebabkan struktur pondasi turbin memang mesti diperkuat untuk mengatasi getaran yang terjadi. Hanya saja, mengingat turbin Darrieus tipe $\mathrm{H}$ menghasilkan daya yang lebih besar, tipe ini tetap bisa diperhitungkan dengan mengupayakan peredaman getaran tadi. Salah satu usahanya adalah memberikan tali penyanggah di bagian atas tiang penyangga turbin (dimana turbin Darrieus tipe Egg-beater-pun memakainya juga), sehingga kita mesti memperhitungkan faktor plusminus dari daya yang dibangkitkan maupun performansi tadi.

Selanjutnya dicoba untuk melihat performansi apa saja yang bisa diselidiki dengan pemodelan ini. Pertama-tama yang akan dilihat adalah bagaimana pengaruh jenis sudu rotor turbin terhadap performansinya. Jadi soliditas (Nc/R) akan diambil 0.1 dan 0.2 untuk tiap-tiap jenis sudu, dengan rasio tinggi turbin terhadap jari-jari ekuatorial $(H / R)=2$ dan $\mathrm{CD} 0=0.0085$ (koefisien drag pada angle of attack sama dengan nol), dan bilangan Reynold (Re) $=0.3 \mathrm{e}+06$. Dan didapatkan hasil antara lain; daya yang dihasilkan, daerah pengoperasian turbin, dan putaran rotor pada sudu NACA 0012 jauh lebih besar ketimbang sudu NACA 0018 (sehingga tidaklah heran bila sudu NACA 0012 lebih sering digunakan ketimbang NACA 0018).

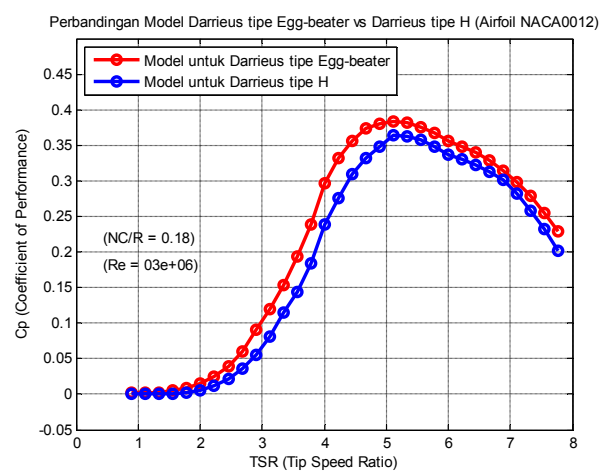

Gambar 4 Perbandingan model Darrieus tipe Eggbeater vs Daarrieus tipe H (NACA 0018)

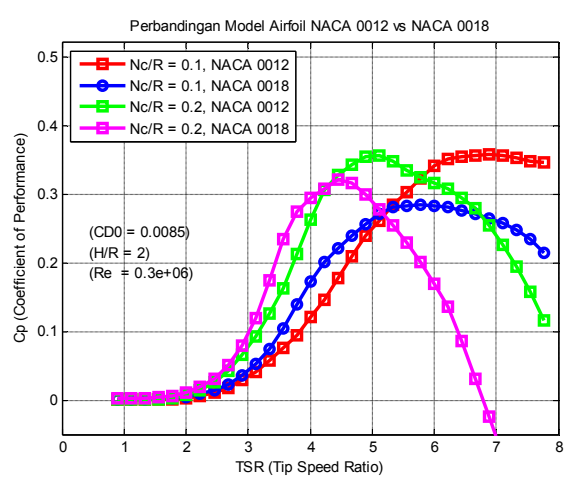

Gambar 5 Perbandingan hasil pemodelan untuk NACA 0012 vs NACA 0018

Kemudian, pengaruh soliditas rotor turbin terhadap performansinya yang akan diteliti. Jadi soliditas $(\mathrm{Nc} / \mathrm{R})$ akan divariasikan dari 0.05 s.d. 0.5 , dengan rasio tinggi turbin terhadap jari-jari ekuatorial $(\mathrm{H} / \mathrm{R})=2$ dan $\mathrm{CD} 0=0.0085$ (koefisien drag pada angle of attack sama dengan nol), dan bilangan Reynold $(\mathrm{Re})=0.3 \mathrm{e}+06$. Dan didapatkan hasil antara lain; pada awalnya daya yang dihasilkan meningkat pada soliditas di kisaran 0.2 lalu menurun kembali begitu soliditasnya dinaikkan, daerah pengoperasian turbinnya melebar pada soliditas rendah (tetapi hal ini malahan mengurangi daya yang dihasilkan), selain itu getaran (stress) pada bagian sudu atas dan bawah juga akan meningkat (pada soliditas yang lebih rendah) karena dengan naiknya nilai TSR maka berarti rotasi sudu-sudunya semakin cepat.

Setelah itu dicoba untuk mengetahui bagaimana pengaruh CD0 (koefisien drag - saat angle of attack $=0)$ terhadap performansinya. Jadi CD0 akan divariasikan dari 0 s.d. 0.025 , dengan bilangan Reynold $(\mathrm{Re})=0.3 \mathrm{e}+06$, rasio tinggi turbin terhadap 
jari-jari ekuatorial $(\mathrm{H} / \mathrm{R})=2$ dan $\mathrm{Nc} / \mathrm{R}=0.2$. Angka ini diambil sesuai dengan analisis di paragraf sebelumnya. Dan didapatkan kesimpulan antara lain; daya yang dihasilkan dan begitu juga putaran rotornya meningkat seiring dengan penurunan nilai CD0 (sehingga nilai CD0 ini harus didesain sekecil mungkin), hanya saja CD0 ini tergantung pada bilangan Reynold-nya sehingga keberadaannya tergantung pada kehalusan permukaan sudusudunya, karena itu proses pabrikasi sudu sangat berperan penting terhadap performansi akhir sudunya.

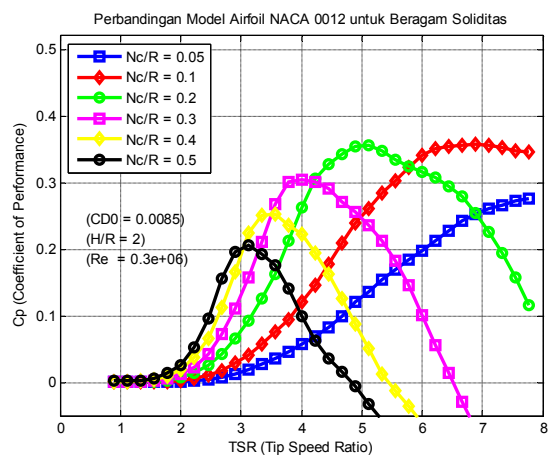

Gambar 6 Perbandingan hasil pemodelan untuk beragam nilai $\mathrm{Nc} / \mathrm{R}(\mathrm{NACA} 0012, \mathrm{Re} \approx 0.3 \mathrm{e}+06$ )

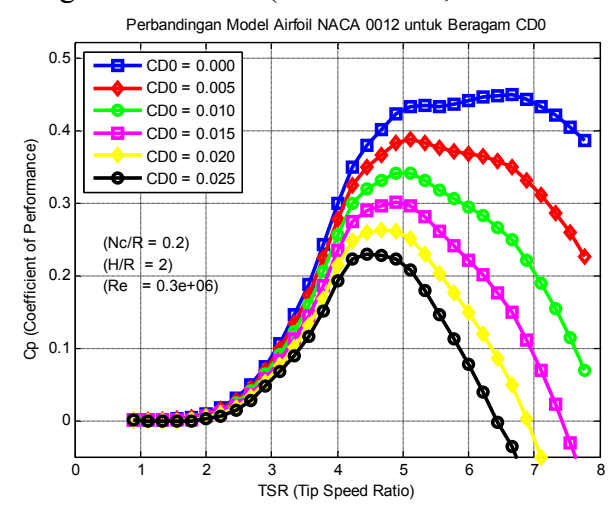

Gambar 7 Perbandingan hasil pemodelan untuk beragam nilai $\mathrm{CD} 0$ (NACA $0012, \mathrm{Re} \approx 0.3 \mathrm{e}+06$ )

\section{KESIMPULAN}

a. Model perencanaan performansi aerodinamika turbin angin Darrieus ini berhasil dibuat dengan hanya berbeda sekitar $0.19 \%$ dengan model sebelumnya dan secara umum cukup memuaskan dan dapat menggambarkan performansi yang diharapkan.

b. Dengan model ini bisa dibuktikan bahwa perbedaan jenis sudu yang dipakai memang mempengaruhi performansi turbinnya, dimana sudu NACA 0012 jauh lebih baik ketimbang sudu NACA 0018.

c. Pemanfaatan swept area belumlah sesuai dengan hasil yang diharapkan walaupun sebenarnya hal ini bisa dimaklumi dengan adanya stress pada bagian atas dan bawah sudu rotornya dan adanya kelemahan teori dasar yang dipakai untuk membuat model ini.

d. Secara teoritis, model ini bisa dipakai untuk memprediksi turbin yang sama dengan mengganti jenis sudu, dimensi, kecepatan angin yang berbeda maupun variabel-variabel lainnya untuk mendapatkan data performansi yang baru yang bisa dipergunakan dalam pendesainan atau perencanaan turbin jenis ini secara eksperimental.

\section{DAFTAR PUSTAKA}

[1] Carrigan, T. J., 2010, "Aerodynamic Shape Optimization of A Vertical Axis Wind Turbine". The University of Texas at Arlington.

[2] Fiedler, A. J., \& Tullis, S., 2009, “Blade Offset and Pitch Effects in A High Solidity Vertical Axis Wind Turbine", Wind Engineering Vol. $33,10$.

[3] Jacobs, N. E., \& Sherman, A., 1937, “Airfoil Section Characteristics as Affected by Variations of The Reynold's Number", National Advisory Commitee for Aeronautics.

[4] Klimas, P. C., \& Worstell, M. H., 1981, "Effect of Blade Preset Pitch Offset on Curved-Blade Darrieus Vertical Axis Wind Turbine Performance', Albuquerque.

[5] Letcher, T., 2010, "Small Scale Wind Turbines Optimized for Low Wind Speeds", 24th Hayes Graduate Research Forum, (p. 21). Ohio.

[6] Ramkissoon, R., \& Manohar, K., 2013, "Increasing The Power Output of The Darrieus Vertical Axis Wind Turbine”, British Journal of Applied Science and Technology, 14. (January 4th, 2013).

[7] Riegels, F. W., 1961, "Aerofoil Sections: Results from Wind Tunnel Investigations Theoritical Foundations', London: Butterworths.

[8] Paraschivoiu, I., 2009, “Wind Turbine Design With Emphasis on Darrieus Concept", Quebec: Presses Internationales Polytechnique.

[9] Kragten, A., 2004, "The Darrieus Rotor, A Vertical Axis WInd Turbine (VAWT) with Only A Few Advantages and Many Disadvantages", Sint-Oedenrode.

[10] Sheldahl, R. E., \& Klimas, P. C., 1981, "Aerodynamic Characteristics of Seven Symmetrical Airfoil Sections Through 180Degree Angle of Attack for Use in 
Aerodynamic Analysis of Vertical Axis Wind Turbines", Albuquerque: Sandia National Laboratories.

[11] Strickland, J. H., 1975, "The Darrieus Turbine: A Performance Prediction Model Using Multiple Streamtubes", Albuquerque. 